As an initial step in addressing the above issues, the AFMRD surveyed its membership regarding maternity care. Specifically, this survey examined such issues as whether a change in ACGME- Residency Review Committee for Family Medicine (RRC-FM) requirements for maternity care was desired, do programs have difficulty meeting RRC-FM Requirements for maternity care, should all family medicine residents have at least some required maternity care experience, and recommendations regarding number of total deliveries needed to better insure competence for a family medicine resident planning on providing maternity care in practice.

To augment the data provided by the survey, a literature review was conducted to provide additional information to AFMRD members in preparation for a discussion forum regarding maternity care and family medicine conducted during the Annual Program Directors Workshop. The literature review provided information regarding issues regarding maternity care in family medicine residency programs, information regarding family medicine residency program graduates and maternity care, the experience of practicing family medicine physicians who are providing maternity care to their patients, and student interest in maternity care.

Next, a facilitated discussion forum regarding maternity care and family medicine was conducted during the Annual Program Directors Workshop in Leawood, Kansas on June 8th, 2008. Using data collected from the previously described survey, 4 program directors were selected to present differing positions on this subject. Following these presentations, an open forum with opinions from the audience was conducted. In particular, specific suggestions to RRC-FM guidelines were requested. During this entire session, information and opinions presented were extracted, reviewed and summarized by members of the AFRMD Board of Directors.

Using the 3 sources of information described above, an initial draft of a Maternity Care Position Statement was developed. This draft statement was presented to the AFMRD membership as well as to representatives from the Society of Teachers of Family Medicine, the Association of Departments of Family Medicine, the North American Primary Care Research Group, and the American Academy of Family Physicians for their review and comment. These comments were collated and presented during an AFMRD Board of Directors meeting. The Board members reviewed and extensively discussed the comments received. Following this meeting, the Position Statement has recently been again revised.

The final version of the Maternity Care Position Statement by the Board of Directors of AFMRD will be forwarded to the Commission on Education (COE) of the AAFP for further review and vetting. The COE will present the final recommendation to the RRC-FFM.

The process used to develop the final position statement to the COE has been deliberate, thoughtful, collaborative, balanced, and methodical. This method is presented as an example of a rational methodology to address significant issues currently present in family medicine education and hopefully will serve as a template for future such deliberations.

Stoney Abercrombie, MD

Paul Callaway, MD

Peter Carek, MD, MS

Sandra Carr, MD,

Gretchen Dickson, MD, MBA

Joseph Gravel, Jr., MD

Karen Hall, MD

Sam Jones, $M D$

Stanley Kozakowski, MD

Elissa Palmer, MD

Mark Robinson, MD

Martin Wieschbaus, MD

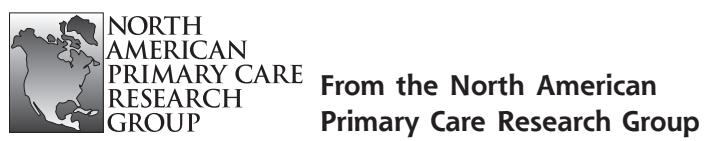

Ann Fam Med 2008;6:570-571. DOI: 10.1370/afm.932.

\section{DEFINITIONS OF COMMON TERMS RELEVANT TO PRIMARY CARE RESEARCH}

\section{Introduction}

The following definitions of terms commonly used by primary care researchers were developed by the Practice-Based Research Subcommittee of the North American Primary Care Research Group (NAPCRG) Committee on Advancing the Science of

Family Medicine(CASFM) after reviewing available definitions, discussions among the members, and advice from outside experts. Establishing a shared terminology is critical for the evolution and growth of primary care research, and these are offered in support of that goal.

Primary care research: Research directed at understanding and improving the primary care function as defined by the Institute of Medicine ("the provision of integrated, accessible healthcare services by clinicians that are accountable for addressing a large majority of personal healthcare needs, developing a sustained partnership with patients, and practicing within the context of family and community"). Primary care research includes theoretical and methodological research, health care research (investigations of the components of the primary care function itself), clinical research, and 
health systems research (including educational research, translational research, and health policy research).

Practice-based research: Research that is grounded in, informed by, and intended to improve practice with the goal of improving the health of patients.

Primary care practice-based research: Research that is grounded in, informed by, and intended to improve primary care practice with the goal of improving the health of patients.

Practice-based research network: A group of separate practices that collaborate with each other and often with outside experts to conduct multiple research projects over an extended period of time while continuing to deliver care to patients.

Primary care practice-based research networks: Practice-based research networks composed primarily of primary care clinicians that focus their research and development activities on issues relevant to the primary care of patients.

Community-based research: Research that is conducted in community settings and is intended to improve community-based interventions and community health.

Participatory research: Research, with the collaboration of those affected by the issue being studied (includes individuals and organizations), for the purpose of taking action or effecting change.

Community-based participatory research: Research conducted with the collaboration of a community for the purpose of taking action or effecting change. The community, in this case, could be any geographically, socio-culturally, or occupationally defined group with common interests and goals. In both participatory research and community-based participatory research, the research questions generally emerge as a result of the attempt to move forward toward a set of objectives, not as the a priori reason for the research.

Efficacy research: Research to determine whether an intervention produces desired results under optimal or near optimal conditions.

Effectiveness research: Research to determine whether an intervention produces desired results under the conditions in which the intervention is likely to be used.

Clinical quality improvement: An interdisciplinary process designed to improve the delivery of preventive, diagnostic, therapeutic, and rehabilitative measures in order to maintain, restore, and improve health outcomes of individuals and populations cost-effectively.

Research translation or knowledge translation: The sequence of events through which a proven scientific discovery moves in a bidirectional fashion between basic scientists, clinical researchers, practitioners, and consumers of health care services.

Translational research: Research that seeks to characterize the sequence of events through which a scientific discovery moves between basic scientists, clinical researchers, practitioners, and consumers, and to find more effective ways to facilitate this process. Translational research can be further specified by the translational phase that it addresses, phase I (basic science to human research or human research to basic science), phase II (human research to practice-based and community-based research or practice-based and community-based research to human research), or phase III (practice-based research to practice and community or practice and community to practice-based research). Phase III translational research is often further divided into dissemination research, implementation research, and diffusion research.

Dissemination research: The study of how the targeted distribution of information and intervention materials to a specific audience can be successfully executed so that increased spread of this knowledge achieves greater use and has increased impact.

Implementation research: The study of how a specific set of activities and designed strategies effect the integration of evidence-based information and interventions into health care and community health practices.

Diffusion research: The study of the factors necessary for successful adoption and implementation by additional stakeholders and the targeted population of an evidence-based intervention that has been successfully implemented in some sites, resulting in widespread use.

James W. Mold, MD, MPH Andy Pasternak, MD, MS Ann McCaulay, CM, MD Donna Manca, MD, MCLSC Guy Rubin, MD Jack Westfall, MD Jobn Beasley, MD Jobn Hickner, MD, MSc L. J. Fagnan, MD Margaret Handley, $\mathrm{PbD}, \mathrm{MPH}$ Richard Haddy, MD Terry Hankey, MD

The authors are members of the Practice-Based Research Subcommittee of the North American Primary Care Research Group Committee on Advancing the Science of Family Medicine. 